\section{Commentary: Moving the goalposts}

\author{
Dawn S. Hui, MD
}

During the past several decades, advances in prehospital care and operative techniques have been systematically instituted in the care of patients with acute type A aortic dissection (TAAD). The resulting improvements in short-term mortality have led to a focus on extending operative techniques to improve mid- and long-term outcomes. Much of this attention has been paid to the prevention of distal degeneration, with antegrade stenting becoming routine at several centers. ${ }^{1-3}$ In contrast, fewer studies have focused on long-term changes in aortic root and valve geometry. Freedom from proximal reoperations has been characterized as high, at $96 \%$ to $99 \%$ at 5 years and $91 \%$ to $98 \%$ at 10 years in Dohle and colleagues, ${ }^{4}$ and $96.1 \%$ at 8 years in the Nordic Consortium Registry. ${ }^{5}$ However, reoperation may not be an exact proxy for aortic root/valve degeneration due to selection bias.

Kim and colleagues ${ }^{6}$ examine the fate of aortic regurgitation after TAAD repair, comparing outcomes of patients who had root replacement with those who had preservation of the root and valve. As described by the authors, the size criterion for root replacement was $>55 \mathrm{~mm}$. The data reported in the study are of value, with $100 \%$ clinical follow-up at 8.6 years and $89 \%$ echocardiographic follow-up at 7.9 years. This type of longitudinal echocardiographic data is typically absent in the large aortic dissection registries. What is known from registry data is that aortic regurgitation of at least moderate degree is not rare, occurring in $18.9 \%$ of TAAD patients in the Society of Thoracic Surgeons database ${ }^{7}$ and $23.3 \%$ of patients in the German Registry for Acute Aortic Dissection Type $\mathrm{A},{ }^{8}$ similar to the $20 \%$ found in the population studied by Kim and colleagues. ${ }^{6}$ This remains then a persistent clinical question for surgeons treating TAAD. The most common approach remains the supracoronary aortic replacement with commissural resuspension. ${ }^{9}$ Still, root replacement in

\footnotetext{
From the Department of Cardiothoracic Surgery, University of Texas Health Science Center at San Antonio, San Antonio, Tex.

Disclosures: Author has nothing to disclose with regard to commercial support.

Received for publication Jan 14, 2020; accepted for publication Jan 14, 2020; available ahead of print Feb 1, 2020

Address for reprints: Dawn S. Hui, MD, Department of Cardiothoracic Surgery, University of Texas Health Science Center at San Antonio, 7703 Floyd Curl Dr, Suite 211L, San Antonio, TX 78229 (E-mail: huid@uthscsa.edu).

J Thorac Cardiovasc Surg 2020;160:1431-2

$0022-5223 / \$ 36.00$

Copyright (C) 2020 by The American Association for Thoracic Surgery

https://doi.org/10.1016/j.jtcvs.2020.01.045
}

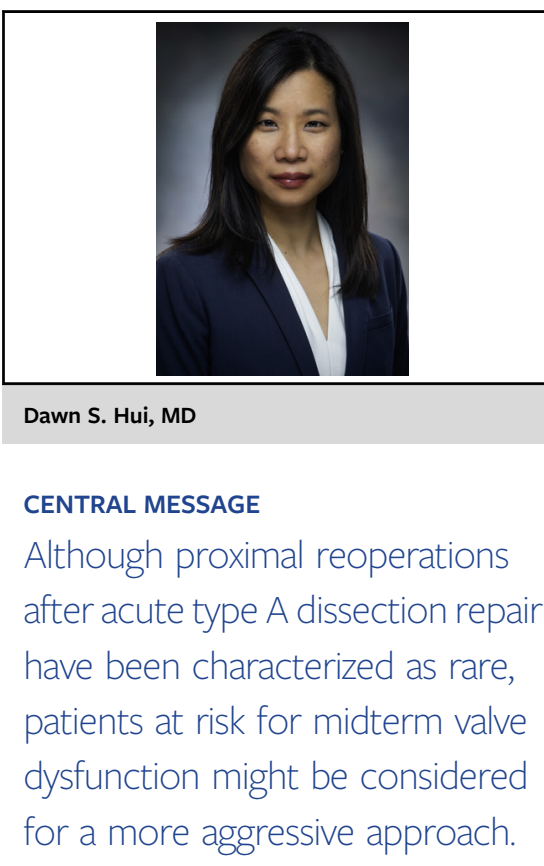

the United States remains fairly frequent at $>25 \%$ in the Society of Thoracic Surgeons database ${ }^{7}$ and even higher in the more recent years of IRAD data. ${ }^{8}$

The article by Kim and colleagues ${ }^{6}$ suggests a slightly different approach reflected in the root replacement rate of only $17 \%$. In the nonroot replacement group, the more conservative approach was associated with respectable short-term mortality outcomes of $9.8 \%$, but a $12.3 \%$ risk of significant aortic insufficiency (AI) and 8.1\% root reoperation at 10 years. Perhaps not surprisingly, preoperative 3 to $4+\mathrm{AI}$ and postoperative $2+\mathrm{AI}$ were significant predictors of $\mathrm{AI}$ and root reoperation at late follow-up, and AI progression was rapid. From this, the authors concluded that careful echocardiogram surveillance is warranted in patients with postoperative $2+\mathrm{AI}$. It is curious that the study findings appear not to have prompted the authors to consider changes to their surgical approach, as others have. ${ }^{10,11}$ Given the authors' similarly respectable operative outcomes with root replacement, it would be a missed opportunity not to consider lowering the threshold for root replacement in patients with severe preoperative AI and significant root dilation. Ro and colleagues ${ }^{11}$ found the cutoff for prediction of late AI to be a diameter of $47 \mathrm{~mm}$. In experienced centers, the extent of proximal operation in TAAD has not been found to be a risk factor for short-term mortality. Another consideration would be avoidance of the use of bioglue, for which increasing data suggest its etiology as a mode of failure. ${ }^{10}$ At the very least, The study by Kim and colleagues $^{6}$ should prompt aortic surgeons in general to consider operative strategies to reduce long-term risk of 
root pathology, just as the field has trended toward reduction of late distal aortic events.

\section{References}

1. Preventza O, Olive JK, Liao JL, Orozco-Sevilla V, Simpson K, Rodriguez MR, et al. Acute type I aortic dissection with or without antegrade stent delivery: mid-term outcomes. J Thorac Cardiovasc Surg. 2019;158:1273-81.

2. Vallabhajosyula P, Szeto WY, Pulsipher A, Desai N, Menon R, Moeller P, et al. Antegrade thoracic stent grafting during repair of acute Debakey type I dissection promotes distal aortic remodeling and reduces late open distal reoperation rate. $J$ Thorac Cardiovasc Surg. 2014;147:942-8.

3. Shi E, Gu T, Yu Y, Yu L, Wang C, Fang Q, et al. Early and midterm outcomes of hemiarch replacement combined with stented elephant trunk in the management of acute DeBakey type I aortic dissection: comparison with total arch replacement. J Thorac Cardiovasc Surg. 2014;148:2125-31.

4. Dohle DS, El Beyrouti H, Brendel L, Pfeiffer P, El-Mehsen M, Vahl CF. Survival and reinterventions after isolated proximal aortic repair in acute type A aortic dissection. Interact Cardiovasc Thorac Surg. 2019;28: 981-8.

5. Pan E, Gudbjartsson T, Ahlsson A, Fuglsang S, Geirsson A, Hansson EC, et al. Low rate of reoperations after acute type A aortic dissection repair from
The Nordic Consortium Registry. J Thorac Cardiovasc Surg. 2018;156: 939-48.

6. Kim DJ, Lee S, Lee SH, Youn YN, Chang BC, Yoo KJ, et al. The fate of residual aortic regurgitation after ascending aorta replacement in type A aortic dissection. J Thorac Cardiovasc Surg. 2020;160:1421-30.e5.

7. Lee TC, Kon Z, Cheema FH. Contemporary management and outcomes of acute type A aortic dissection: an analysis of the STS Adult Cardiac Surgery Database. J Card Surg. 2018;33:7-18.

8. Conzelmann LO, Weigang E, Mehlhorn U, Abugameh A, Hoffmann I, Blettner M, et al. Mortality in patients with acute aortic dissection type A: analysis of pre- and intraoperative risk factors from the German Registry for Acute Aortic Dissection Type A (GERAADA). Eur J Cardiothorac Surg. 2016;49: e44-52.

9. Parikh N, Trimarchi S, Gleason TG. Changes in operative strategy for patients enrolled in the International Registry of Acute Aortic Dissection interventional cohort program. J Thorac Cardiovasc Surg. 2017;153:S74-9.

10. De Paulis R, Cetrano E, Moscarelli M, Andò G, Bertoldo F, Scaffa R, et al. Effects of ascending aorta replacement on aortic root dilatation. Eur $J$ Cardiothorac Surg. 2005;27:86-9.

11. Ro SK, Kim JB, Hwang SK, Jung SH, Choo SJ, Chung CH, et al. Aortic root conservative repair of acute type A aortic dissection involving the aortic root: fate of the aortic root and aortic valve function. J Thorac Cardiovasc Surg. 2013;146:1113-8.
See Article page 1421.

\section{Commentary: Progressive aortic valve regurgitation after replacement of the dissected ascending aorta: An unsolved dilemma}

Oliver J. Liakopoulos, MD, ${ }^{a}$ and Yeong-Hoon Choi, $\mathrm{MD}^{\mathrm{b}}$

Despite significant improvements in surgical outcomes during the past 2 decades, type A acute aortic dissection (AAD) remains a life-threatening disease linked to a substantial mortality and morbidity. In a recent overview article

From the a Department of Cardiothoracic Surgery, Heart Center, University of Cologne, Cologne, Germany; and the ${ }^{b}$ Department of Cardiac Surgery, Kerckhoff Heart Center, University of Giessen, Campus Bad Nauheim, Bad Nauheim, Germany.

Disclosures: Authors have nothing to disclose with regard to commercial support.

Received for publication Jan 26, 2020; accepted for publication Jan 26, 2020; available ahead of print Feb 1, 2020.

Address for reprints: Oliver J. Liakopoulos, MD, Department of Cardiothoracic Surgery, Heart Center, University of Cologne, Kerpener Strasse 62, 50924 Cologne, Germany (E-mail: oliver.liakopoulos@uk-koeln.de).

J Thorac Cardiovasc Surg 2020;160:1432-3

$0022-5223 / \$ 36.00$

Copyright (c) 2020 by The American Association for Thoracic Surgery

https://doi.org/10.1016/j.jtcvs.2020.01.044
Check for updates

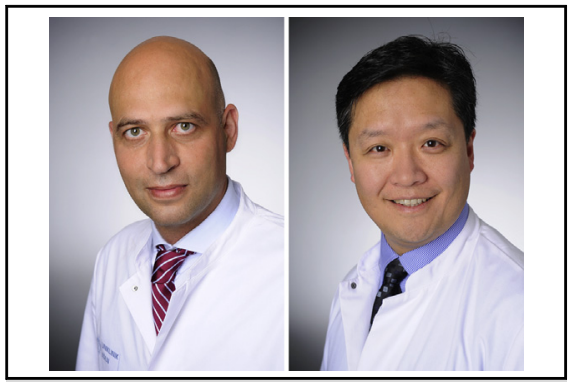

Oliver J. Liakopoulos, MD, and Yeong-Hoon Choi, MD

\section{CENTRAL MESSAGE}

This single-center retrospective analysis provides new insights of long-term durability of ascending aortic replacement in patients presenting with type A acute aortic dissection.

from the investigators of the International Registry of Acute Aortic Dissection (IRAD) that was initiated in 1996 and prospectively analyzes outcome data from more than 50 international sites with, so far, more than 7300 patients with acute type A and B aortic dissection, a significant temporal decline of surgical mortality rate from $25.0 \%$ 